\title{
RESEARCH
}

Open Access

\section{Pharmacological neuroenhancement and the ability to recover from stress - a representative cross-sectional survey among the German population}

Christiana Bagusat $^{1 *}$, Angela Kunzler ${ }^{1,2}$, Jennifer Schlecht ${ }^{1}$, Andreas G. Franke ${ }^{3}$, Andrea Chmitorz ${ }^{1,2+}$ and Klaus Lieb ${ }^{1,2+}$

\begin{abstract}
Background: Pharmacological neuroenhancement (PNE) refers to the use of psychoactive substances without doctor's prescription to enhance cognitive performance or to improve mood. Although some studies have reported that drugs for PNE are also being used to cope with stressful life situations, nothing is known about the relationship of PNE and resilience, i.e. the ability to recover from stress. This study aimed at investigating the relationship of PNE and resilience in the first representative population sample.

Methods: A cross-sectional survey in a representative sample of 1128 adults (age $\geq 18$ yrs.) living in Germany was conducted. The use of PNE and related attitudes, perceptions and behaviours were assessed by structured interviews and self-report questionnaires. Stepwise logistic regression with backward elimination was conducted to identify potential risk factors for PNE use.

Results: Lifetime prevalence for the use of stimulating prescription drugs without medical indication was 4.3\%, $10.2 \%$ for stimulating illicit drugs, 20.3\% for mood modulating prescription drugs, and $23.4 \%$ for cannabis. Coping with stressful situations was more frequently reported as underlying motive for using stimulant or mood modulating prescription drugs than stimulating illicit drugs or cannabis. The individual perceived stress increased the risk of using stimulating prescription drugs (OR: $2.86 ; 95 \% \mathrm{Cl}: 1.49-5.46)$ and the individual ability to recover from stress decreased the risk of using any substance for PNE and especially mood modulating prescription drugs (OR: .62; 95\% Cl: .47-.81).

Conclusions: The non-medical use of prescription drugs for PNE appears to be more prevalent in subjects who are less resilient to stress. Tailored resilience interventions that improve the ability to adapt to and recover from stressors may prevent the use of prescription medication for PNE. Further research should disentangle the association between psychological resilience and PNE as well as examine the efficacy of resilience interventions in the prevention of PNE.
\end{abstract}

Keywords: Pharmacological neuroenhancement, Resilience, Stress coping, Illicit drugs, Prescription drugs

\footnotetext{
* Correspondence: bagusat@uni-mainz.de

${ }^{\dagger}$ Andrea Chmitorz and Klaus Lieb contributed equally to this work.

'Department of Psychiatry and Psychotherapy, University Medical Center

Mainz, Untere Zahlbacher Str. 8, 55131 Mainz, Germany

Full list of author information is available at the end of the article
}

(c) The Author(s). 2018 Open Access This article is distributed under the terms of the Creative Commons Attribution 4.0 International License (http://creativecommons.org/licenses/by/4.0/), which permits unrestricted use, distribution, and reproduction in any medium, provided you give appropriate credit to the original author(s) and the source, provide a link to the Creative Commons license, and indicate if changes were made. The Creative Commons Public Domain Dedication waiver (http://creativecommons.org/publicdomain/zero/1.0/) applies to the data made available in this article, unless otherwise stated. 


\section{Background}

Pharmacological neuroenhancement (PNE) refers to the use of psychoactive substances without medical indication to enhance cognitive performance or to improve mood [1-3]. Several studies have investigated the prevalence of PNE in different at risk populations such as pupils [4-6], students [4, 7-13], academics [14], chess players [15] or physicians [16]. International studies found divergent lifetime prevalences between 1 and 20\% $[4,7,16-20]$ which are dependent on the sample being investigated, the definition of PNE, the drugs questioned, and the survey technique used. Most studies have investigated PNE as a mode to enhance cognitive performance by the use of stimulating prescription or illicit drugs such as modafinil and methylphenidate or amphetamines, respectively. Other studies have also measured the use of mood modulating drugs such as antidepressants by non-depressed healthy subjects to improve mood or reduce nervousness and found lifetime prevalence rates between 5 and $15 \%[1,16]$. Data about the effectiveness of such substances are very different $[2,21]$.

Depending on the authors of scientific articles some consider PNE to be "a bad thing "which could harm individuals and change - in a negative way - society, however, others would favour the use of PNE drugs based on the ancient wish of mankind to enhance oneself $[22,23]$.

Research on the use of PNE as a strategy to cope with stressful life situations has been rather neglected so far. There is some evidence that PNE is associated with the level of perceived stress. Middendorff and colleagues [11] conducted a survey with over 7.000 students in Germany. Among those students who reported feeling no or a low pressure to perform at university, only $3 \%$ have already used prescription or illicit drugs for PNE at least once, whereas $9 \%$ of students feeling high pressure to perform have already used such medication or drugs [11]. In an online survey among the Swiss population, PNE was also positively associated with frequent stress in the past 12 months [10]. Other studies could demonstrate correlations between perceived stress and PNE among specific professions [24]. Surgeons' pressure to perform at work and stress in private life were positively associated with PNE or mood enhancement [16]. In addition, work-related stress increased the willingness to use PNE-drugs in a study among university teachers [24]. Schröder and colleagues [25] compared users and non-users of PNE in physicians, publicists, advertising experts and programmers in Germany in the last 12 months. They found higher cognitive stress symptoms among PNE-users compared to non-users.

All these studies investigated the associations between perceived life stress and prevalence rates for PNE use. However, no study assessed the substance use for PNE in subjects who are able to recover from stress to varying degrees. This ability is closely related to the construct of psychological resilience, i.e., the well-observed phenomenon that many people do not or only temporarily become mentally ill despite significant adversity (e.g., [26-29]). Although previously considered as a stable personality trait (e.g., a "hardy" person), resilience is nowadays seen as modifiable outcome or dynamic process with personality as one of many risk or protective factors for maintaining or regaining mental health $[30,31]$. Resilience is partially determined or predicted by multiple resilience factors [30], i.e., resources which protect a person from the potential negative effect of encountered stressors by modifying the individual's response to stress and adversities [32, 33]. These include internal factors, such as (resilience-conducive) personality traits (e.g., optimism, hardiness), beliefs (e.g., self-efficacy), as well as external factors such as social support or socioeconomic status [34,35]. Although there is evidence that some of the internal and external resilience factors are related to PNE use [11, 24, 36] the effect of the individual ability to recover from stress on PNE use is unknown so far.

In order to overcome limitations of previous surveys on PNE use regarding resilience factors, we performed a quantitative study on the relationship between the ability to recover from stress and PNE use in a representative sample of the German population. In addition, we assessed the association of PNE use with three well-evidenced resilience factors (self-efficacy, locus of control and optimism) [37, 38].

\section{Methods}

\section{Participants and procedure}

We conducted a cross-sectional representative survey of the German population between August 19th and September 19th 2016 regarding attitudes, perceptions and behaviours referring to PNE. Face-to-face interviews of approximately $30 \mathrm{~min}$ length were conducted in 1128 people at participant's place (minimum age: 18 years). The individuals were selected by the "Institut für Demoskopie Allensbach" as they met criteria of the quota sample based on the German official statistics regarding central socio-demographic factors [39]. This procedure was chosen to increase the generalizability of the results for the German population. Participants were informed by professional interviewers about the objectives of the study, the procedure of data storage and confirmed their voluntary participation verbally. To help to assure confidentiality, there was no written consent. To ensure that each question is comprehensible, the standardized questionnaire was pretested and optimised.

The interviewers were trained uniformly to answer further questions if necessary for example if there were 
uncertainties in the understanding of terms such as "better cognitive performance". Hence they especially clarified that the questions regarding PNE do not concern the intake of medication by doctor's prescription. The questionnaire included a section assessing socio-demographic data such as gender, age, school education, current or last professional position, employment status, working hours, shift work, federal state of residence, size place of residence and soft enhancer intake.

Also there were questions regarding the perception of the topic PNE in the media, ethical questions and socio-psychological aspects which will be published separately.

Beside questions that were directly asked by the interviewer, the questionnaire also included a section that had to be completed written and returned hidden in an envelope to the interviewer to increase the reliability of the prevalence rates of PNE use. As these questions referred to the individual consumption of psychoactive substances to increase individual performance, this procedure guaranteed confidentiality for the respondent regarding these sensitive questions. The study was approved by the local Ethics Committee (Landesärztekammer Rheinland-Pfalz, No 837.209.14, 9448F), and there was no remuneration of the participating subjects.

\section{Assessment of prevalence of PNE and reasons and goals for intake}

The questionnaire to assess the prevalence of PNE as well as goals and attitudes towards PNE by our group was based on experiences with earlier surveys $[4,16]$ and other published data.

\section{Assessment of prevalence of PNE}

To estimate the prevalence of PNE, we asked two main questions: The first question referred to enhancement by the intake of freely available substances that can be bought in supermarkets or pharmacies without any prescription such as energy drinks, Ginkgo biloba or caffeine tablets. The interviewer asked: "There are various substances mentioned on this list. Are there any that you have taken or are currently taking to improve your mental performance, improve your mood, relieve anxiety or nervousness, or manage stress? You only have to tell me the corresponding numbers from the list." The second question referred to the use of prescription and/or illicit drugs. It was assessed within the self-completed anonymous paper-and pencil-section. Out of 1128 respondents, 86 had never heard of the phenomenon of PNE. Thus they were assigned to the group of "non-users" in the further analysis. Hence 1042 had been asked for their use of prescription/illicit substances for PNE.

Here, the interviewer asked: "Here are some drugs that can be used to improve cognitive performance, improve mood, relieve anxiety or nervousness, or to manage stress. Please tick every drug if you have already taken it for the above-mentioned purpose without medical indication. If you have already taken a drug, please indicate when and how often." The list of substances included prescription drugs, such as methylphenidate (e.g., Ritalin ${ }^{\oplus}$ ) or modafinil, and illicit substances such as cocaine or amphetamines. All substances were clustered into three substance groups (stimulants, mood enhancer and cannabis). For a more differentiated consideration "stimulants" were divided into "prescription stimulants" and "illicit stimulants" for further analysis. If one substance of a substance group was used at least once for PNE, the respondent was asked to answer further questions about the use. If more than one substance of a substance group was used, it was asked to choose the most important substance of that group and the respondent had to answer further questions about the use only for that substance of the group.

\section{Assessment of reasons and goals for PNE}

Beside the frequency of intake, participants were also asked for the reason of their use and which goals they pursued by the intake of the substance. The two questions were asked for one substance of each substance group. If they used multiple substances of one group (stimulants, mood enhancer, cannabis) they were asked to indicate reasons and goals only for the use of the most important one. They were asked: "For what reason did you take this drug? Please tick for every reason stated to what extend this applies to you." and "What were you trying to achieve by taking this drug? Please tick for every reason stated to what extend this applies to you." Users could rate the importance of different reasons and goals for the intake of the substance on a five-point Likert scale ( $1=\mathrm{I}$ totally agree; $5=\mathrm{I}$ totally disagree) e.g., "I wanted to improve mood" or" I wanted to be able to handle stressful situations better". The coding of items was reversed ( 1 = I totally disagree; $5=$ I totally agree $)$ before calculating mean values thus higher values mean higher importance of the reason or goal for the substance use. As individuals might be part of different substance groups there are no $p$-values to estimate statistical significance of mean values.

Questionnaires to assess the ability to recover from stress, perceived stress and related psychological resilience factors To allow for analyses of the association between PNE and the ability to cope with stress, different assessment scales were used:

\section{Brief Resilience Scale (BRS) [40]}

The scale consists of six items assessing self-ratings of the individual ability to recover from stress despite 
significant adversity (item 1" I tend to bounce back quickly after hard times", item 2" I have a hard time making it through stressful events", item 3" It does not take me long to recover from a stressful event", item 4" It is hard for me to snap back when something bad happens", item 5" I usually come through difficult times with little trouble" and item 6" I tend to take a long time to get over set-backs in my life"). The items are rated on a five-point Likert scale ( 1 = strongly disagree; 5 = strongly agree). Item 1,3 , and 5 are positively phrased; items 2,4 , and 6 are negatively phrased. The coding of the negatively phrased items is reversed in order to calculate the mean (range: 1-5) of the six items [40]. Higher values indicate a higher ability to recover from stress. We used the German version of the instrument, which was recently validated in a population of $n=2.609$ German participants [41]. The psychometric data of the BRS ratings of the sample investigated here were part of this validation study.

\section{Perceived Stress Scale (PSS-4) [42]}

The PSS-4 consists of four items measuring the individual evaluation of stressful situations in the previous 12 months (item 1 "How often have you felt that you were unable to control the important things in your life?", item 2.

"How often have you felt confident about your ability to handle your personal problems?", item 3 "How often have you felt that things were going your way?", item 4 "How often have you felt difficulties were piling up so high that you could not overcome them?"). The items are rated on a five-point Likert scale $(1=$ never; $5=$ very often). Item 2 and 3 are reverse coded and were recoded for the analysis. For each subject, sum scores across all items are calculated (range: $0-16$ ). Higher values indicate more perceived stress. We used the German version of the scale [43].

\section{Short Scale for Measuring General Self-efficacy Beliefs (ASKU) [44]}

The questionnaire consists of three positively worded items assessing self-rated confidence in the individual ability to achieve intended results ("I can rely on my own abilities in difficult situations", "I am able to solve most problems on my own", "I can usually solve even challenging and complex tasks well") rated on a five-point Likert scale $(1=$ does not apply at all; $5=$ applies completely $)$. Mean scores are used for analysis (range: 1-5). Higher values indicate higher self-efficacy.

Short Scale for the Assessment of Locus of Control (IE) [45] The four-item scale assesses internal and external control beliefs (internal control beliefs: "I'm my own boss", "If I work hard, I will succeed"; external control beliefs:
"Whether at work or in my private life: What I do is mainly determined by others", "Fate often gets in the way of my plans"). The questions are rated on a five-point Likert scale $(1=$ does not apply at all; $5=$ applies completely). Mean scores for internal or external control are calculated (range: 1-5). Higher values indicate higher internal (items 1 and 2) or external (items 3 and 4) control beliefs.

\section{Optimism-Pessimism-2 Scale (SOP-2) [46]}

The questionnaire consists of two items assessing self-rated optimism ("How optimistic are you in general?") and pessimism ("How pessimistic are you in general?"). The questionnaire uses a seven-point Likert scale (optimism: 1 = not at all optimistic; 7 = very optimistic; pessimism: 1 = not at all pessimistic; $7=$ very pessimistic). To calculate the mean of the two items, reverse scoring of the item pessimism is used (range: 1-7).

\section{Statistical analyses}

Analyses were performed with SPSS for Windows, Version 17.0. To guarantee representativeness to the highest possible standard, data of respondents included in the final sample was weighted for the area and federal states of Germany, size of the town, gender, school education, age and profession. $\mathrm{N}$ values of weighted data were rounded. Differences between users or subgroups of users and non-users in sociodemographic variables (gender, age, education, current or last professional position, employment status, working hours, shift work, federal state of residence, size place of residence and soft enhancer intake) were analysed using $\mathrm{chi}^{2}$-test, Fisher's exact test, t-test and Welch test. Variables referring to the importance of reasons and goals were recoded for analysis $(1=I$ totally disagree; $5=I$ totally agree). Means are reported with standard deviations (SD).

In order to assess the associations between PNE use and the ability to recover from stress, perceived stress and resilience factors (self-efficacy, control beliefs and optimism), stepwise logistic regression with backward elimination was conducted to determine predictors of PNE consumption using the most parsimonious model. Prior to multivariate analyses, means of users (and respective subgroups) with nonusers were compared using $\mathrm{t}$-tests for continuous variables to assess the associations between each of the potential predictors (BRS, PSS-4, ASKU, IE internal, IE external, SOP-2) with PNE use. To test for multicollinearity, associations between the predictor variables (Pearson correlations) were examined and the variance inflation index (VIF) calculated. According to the literature, the correlations should not exceed .80, the VIF should not exceed 10 [47]. 
In the multivariate model, all predictors (BRS, PSS-4, ASKU, IE internal, IE external, SOP-2) were excluded stepwise. In order to control for potential confounders, sociodemographic variables (gender, age, education, current or last professional position, employment status, working hours, shift work, federal state of residence, size place of residence, soft enhancer intake) with a statistically significant mean difference between users or subgroups of users and non-users $(p<.1)$ were included at once (method: enter) from the first step on in the model. Continuous variables (age, BRS, PSS-4, IE external, IE internal, SOP-2 and ASKU) were $\mathrm{z}$-transformed. The significance level was $p<0.05$.

\section{Results}

\section{Sample characteristics}

The total sample consists of $n=1128$ subjects. Table 1 gives sociodemographic information for users and non-users of PNE.

\section{Prevalence rates for the use of substances for PNE}

Most participants were familiar with the phenomenon of taking drugs or other substances for PNE $(n=1042$; 92.4\%). Table 2 summarizes the prevalence rates of the use of prescription and illicit drugs for PNE in the representative sample.

As one person is assigned to a substance-group via lifetime use of relevant substances, it is possible that individuals are part of several clustered substancegroups (Table 2).

Overall, lifetime use ("at least once") of any prescription or illicit drug for cognitive or mood enhancement was $38.8 \%$, with a last year, last month, and last week prevalence of $19.1 \%, 10.1 \%$, and $8.5 \%$, respectively (Table 2). Regarding different substance categories, the highest lifetime prevalence was found for cannabis (23.4\%) followed by mood modulating prescription drugs (20.3\%) and stimulating illicit drugs (10.2\%). Stimulating prescription drugs had the lowest lifetime prevalence (4.3\%) compared to the other substance groups (see Table 1). However, last year, last month and last week prevalence was higher for mood modulating prescription drugs $(10.6 \% / 5.9 \% / 5.6 \%)$ than for cannabis $(8.6 \%$ / 3.7\% / 2.8\%), stimulating illicit drugs $(3.8 \% / 1.3 \% / 0.6 \%)$ and stimulating prescription drugs $(2.2 \% / 0.8 \% / 0.3 \%)$.

\section{Reasons and goals for PNE}

Coping with stressful situations was a relevant motive for the intake of substances for PNE, but this varied between substance groups. Users of prescription drugs agreed to a higher extent that stress coping was a reason for their use (stimulating prescription drugs: $M=3.57$, $\mathrm{SD}=1.39$; mood modulating prescription drugs: $\mathrm{M}=$ $3.16, \mathrm{SD}=1.65$ ) than users of illicit drugs (stimulating illicit drugs $\mathrm{M}=2.43, \mathrm{SD}=1.52$; cannabis: $\mathrm{M}=2.04$, $\mathrm{SD}=1.43$ ) (see Fig. 1). On the other hand, users of illicit drugs agreed to a higher extent that their goal for the intake was to improve mood (stimulating illicit drugs $\mathrm{M}=$ 4.26, $\mathrm{SD}=1.16$; cannabis: $\mathrm{M}=4.12, \mathrm{SD}=1.28$ ) compared to users of prescription drugs (stimulating prescription drugs: $\mathrm{M}=3.32, \mathrm{SD}=1.44$; mood modulating prescription drugs: $\mathrm{M}=3.23, \mathrm{SD}=1.66$ ).

\section{Stress, the ability to recover from stress and resilience factors in users and non-users of substances for PNE}

The ability to recover from stress and the level of perceived stress differed between users $(n=435)$ and non-users $(n=686)$ of any prescription or illicit drug (see Additional file 1): Users had a lower ability to recover from stress than non-users as measured by the Brief Resilience Scale (BRS) (user: $\mathrm{M}=3.19, \mathrm{SD}=.96$; non-user: $\mathrm{M}=3.46, \mathrm{SD}=.93 ; p<0.001)$. This difference was also shown in the subgroups 'stimulating prescription drugs' and 'mood modulating drugs' but not in the subgroups 'stimulating illicit drugs' or 'cannabis' (see Additional file 1). Users also reported more perceived stress than non-users as measured by the Perceived Stress Scale (PSS-4) (user: $\mathrm{M}=7.46, \mathrm{SD}=2.87$; non-user: $\mathrm{M}=6.70, \mathrm{SD}=2.79, p<.01)$. The same results were found for all subgroups of PNE users (i.e., stimulating prescription drugs, stimulating illicit drugs, mood modulating drugs and cannabis) (see Additional file 1). Furthermore, compared to non-users, users showed lower values in the three resilience factors. As indicated by the mean scores in the Optimism-Pessimism-2 Scale (SOP-2), users were less optimistic than non-users (user: $\mathrm{M}=4.83, \quad \mathrm{SD}=1.21 ; \quad$ non-user: $\mathrm{M}=5.08, \quad \mathrm{SD}=1.19$, $p<.01)$ overall as well as in all subgroups of PNE users (see Additional file 1).

In addition, users showed lower self-efficacy beliefs than non-users (user: $\mathrm{M}=3.89, \mathrm{SD}=.70$; non-user: $\mathrm{M}=$ $4.02, \mathrm{SD}=.72, p<.01$ ), as assessed by the Short Scale for Measuring General Self-efficacy Beliefs (ASKU). This result was found in all subgroups of PNE users (see Additional file 1). Furthermore, compared to non-users, users had lower internal locus of control (user: $M=4.11$, $\mathrm{SD}=.74$; non-user: $\mathrm{M}=4.23, \mathrm{SD}=.69, p<.05)$ and higher external locus of control (user: $\mathrm{M}=2.59, \mathrm{SD}=.83$; non-user: $\mathrm{M}=2.38, \mathrm{SD}=.82, p<.01$ ), as measured by the Short Scale for the Assessment of Locus of Control (IE). For internal locus of control, the same difference was only identified for the subgroups 'mood modulating drugs' and 'cannabis' but not for the subgroups 'stimulating prescription drugs' and 'stimulating illicit drugs' (see Additional file 1). External locus of control was higher in users compared to non-users in all subgroups (Additional file 1). 
Table 1 Sociodemographic characteristics for users and non-users in the representative survey of the German population

\begin{tabular}{|c|c|c|c|c|c|c|c|c|c|}
\hline & \multicolumn{4}{|c|}{ Any medication or drug $(n=435)$} & \multicolumn{4}{|c|}{ Non-User $(n=686)$} & \multirow[t]{4}{*}{$p$-value } \\
\hline & \multicolumn{3}{|l|}{ Weighted $^{a}$} & \multirow{3}{*}{$\begin{array}{l}\text { Unweighted } \\
\% \text { (n) }\end{array}$} & \multicolumn{3}{|l|}{ Weighted $^{a}$} & \multirow{3}{*}{$\begin{array}{l}\text { Unweighted } \\
\% \text { (n) }\end{array}$} & \\
\hline & \multirow[t]{2}{*}{$\%(n)$} & \multicolumn{2}{|c|}{$95 \% \mathrm{Cl}$} & & \multirow[t]{2}{*}{$\%(n)$} & \multicolumn{2}{|c|}{$95 \% \mathrm{Cl}$} & & \\
\hline & & $\min$ & $\max$ & & & $\min$ & $\max$ & & \\
\hline Age & $47.7(17.7)$ & 46.0 & 49.3 & $48.0(17.6)$ & $53.4(18.1)$ & 52.0 & 54.8 & $52.9(17.9)$ & 0.01 \\
\hline Gender & & & & & & & & & 0.06 \\
\hline Male & $51.7(225)$ & 47.0 & 56.4 & $49.9(217)$ & $46.0(316)$ & 42.3 & 49.7 & $45.9(315)$ & \\
\hline Female & $48.3(210)$ & 43.6 & 53.0 & $50.1(218)$ & $54.0(371)$ & 50.3 & 57.7 & $54.1(372)$ & \\
\hline Education & & & & & & & & & 0.82 \\
\hline No formal degree & $1.4(6)$ & 0.3 & 2.5 & $1.2(5)$ & $1.6(11)$ & 0.7 & 2.6 & $1.3(9)$ & \\
\hline Secondary modern school ${ }^{\mathrm{b}}$ & $31.3(133)$ & 26.9 & 35.7 & $24.4(104)$ & $33.2(227)$ & 29.7 & 36.8 & $26.1(178)$ & \\
\hline Middle school ${ }^{c}$ & $30.4(129)$ & 25.9 & 34.7 & $31.5(134)$ & $30.9(211)$ & 27.4 & 34.4 & $31.2(213)$ & \\
\hline University-entrance diploma ${ }^{d}$ & $17.7(75)$ & 14.0 & 21.3 & $23.7(101)$ & $17.7(121)$ & 14.9 & 20.6 & $22.9(156)$ & \\
\hline University degree & $19.3(82)$ & 15.5 & 23.1 & $19.2(82)$ & $16.5(113)$ & 13.8 & 19.3 & $18.5(126)$ & \\
\hline Current or last professional position & & & & & & & & & 0.23 \\
\hline No employment yet & $5.3(23)$ & 3.2 & 7.4 & $5.8(25)$ & $4.5(31)$ & 3.0 & 6.1 & $5.0(34)$ & \\
\hline Skilled worker & $14.4(62)$ & 11.1 & 17.7 & $14.4(62)$ & $14.2(97)$ & 11.6 & 16.8 & $13.5(92)$ & \\
\hline Executive employee & $10.7(46)$ & 7.7 & 13.6 & $10.9(47)$ & $14.2(97)$ & 11.6 & 16.8 & $14.5(99)$ & \\
\hline Non-executive employee & $43.3(187)$ & 38.6 & 48.0 & $42.1(182)$ & $44.0(300)$ & 40.3 & 47.7 & $43.4(296)$ & \\
\hline Civil servants & $5.6(24)$ & 3.4 & 7.7 & $6.7(29)$ & $6.5(44)$ & 4.6 & 8.3 & $7.6(52)$ & \\
\hline Self-employed & $6.0(26)$ & 3.8 & 8.3 & $6.5(28)$ & $3.4(23)$ & 2.0 & 4.7 & $3.7(25)$ & \\
\hline Other & $14.8(64)$ & 11.5 & 18.2 & $13.7(59)$ & $13.2(90)$ & 10.7 & 15.7 & $12.3(84)$ & \\
\hline Shift work & & & & & & & & & 0.14 \\
\hline Yes & $15.4(44)$ & 11.2 & 19.6 & $15.5(44)$ & $20.0(75)$ & 15.9 & 24.0 & $19.7(74)$ & \\
\hline No & $84.6(241)$ & 80.4 & 88.8 & $84.5(240)$ & $80.0(301)$ & 76.0 & 84.1 & $80.3(302)$ & \\
\hline Weekly working hours & & & & & & & & & 0.73 \\
\hline Currently not working & $34.0(147)$ & 29.6 & 38.5 & $34.0(147)$ & $44.8(307)$ & 41.1 & 48.5 & $44.8(307)$ & \\
\hline$<20 \mathrm{~h}$ & $6.7(19)$ & 3.8 & 9.6 & $6.3(18)$ & $4.3(16)$ & 2.2 & 6.4 & $4.3(16)$ & \\
\hline $20-29$ & $8.8(25)$ & 5.45 & 12.1 & $8.5(24)$ & $9.9(37)$ & 6.9 & 13.0 & $9.4(35)$ & \\
\hline $30-40$ & $50.5(144)$ & 44.2 & 56.3 & $50.4(143)$ & $50.4(188)$ & 45.3 & 55.5 & $49.9(186)$ & \\
\hline $41-50$ & $24.9(71)$ & 19.9 & 29.9 & $25.4(72)$ & $25.7(96)$ & 21.3 & 30.2 & $26.5(99)$ & \\
\hline$>50$ & $9.1(26)$ & 5.8 & 12.5 & $9.5(27)$ & $9.7(36)$ & 6.7 & 12.7 & $9.9(37)$ & \\
\hline Size place of residence (inhabitants) & & & & & & & & & 0.01 \\
\hline$<2.000$ & $7.8(34)$ & 5.3 & 10.3 & $6.9(30)$ & $8.3(57)$ & 6.2 & 10.4 & $6.6(45)$ & \\
\hline $2.000-20.000$ & $29.7(129)$ & 25.4 & 34.0 & $29.2(127)$ & $37.3(256)$ & 33.7 & 40.9 & $34.5(237)$ & \\
\hline $20.000-100.000$ & $25.8(112)$ & 21.6 & 29.9 & $26.9(117)$ & $28.7(197)$ & 25.3 & 32.1 & $31.7(218)$ & \\
\hline$>100.000$ & $36.8(160)$ & 32.3 & 41.3 & $37.0(161)$ & $36.8(176)$ & 32.3 & 41.3 & $27.2(187)$ & \\
\hline Soft enhancer intake & & & & & & & & & 0.01 \\
\hline yes & $86.3(372)$ & 83.1 & 89.6 & $86.3(372)$ & $49.5(334)$ & 45.7 & 53.3 & $50.4(341)$ & \\
\hline no & 13.7 (59) & 6.6 & 20.8 & 13.7 (59) & 50.5 & 46.7 & 54.3 & 49.6 (336) & \\
\hline
\end{tabular}

$N=1128$. Data are given in \% with numbers of subjects in parentheses. For age, means with SD in parentheses are given. ${ }^{\text {a }}$ weighted according to the distribution of the general population in Germany as reported by the German Office of National Statistics; bequivalent to German "Hauptschule" degree after 9 years of formal education; 'equivalent to German "Realschule" degree after 10 years of formal education; 'equivalent to German general or subject-specific. "Hochschulreife" or "Fachhochschulreife" degree (entrance qualifications for university or university of applied sciences) after 11. Twelve or 13 years of formal education; $p$-values: statistically significant differences between the respective group of users and non-users $(a=.05)$; weighted $\mathrm{n}$ is rounded; weighted $\%$ refers to valid answers 
Table 2 Use of prescription and illicit drugs to enhance cognitive performance or mood without medical indication

\begin{tabular}{|c|c|c|c|c|c|}
\hline Substance group / Single substances ${ }^{a}$ & $n^{b}$ & Lifetime $\%^{c}(n)$ & Last year $\%^{\mathrm{c}}(\mathrm{n})$ & Last month $\%^{\mathrm{c}}(\mathrm{n})$ & Last week $\%^{\mathrm{c}}(\mathrm{n})$ \\
\hline Stimulating prescription drugs & 1115 & $4.3(48)$ & $2.2(25)$ & $0.8(9)$ & $0.3(4)$ \\
\hline Prescription drug containing amphetamines & 1112 & $1.7(19)$ & $0.8(9)$ & $0.3(4)$ & - \\
\hline Methylphenidate & 1110 & $2.2(25)$ & $1.1(12)$ & $0.3(3)$ & $0.1(1)$ \\
\hline Anti-dementia drug & 1110 & $1.0(11)$ & $0.6(6)$ & $0.2(2)$ & $0.2(2)$ \\
\hline Modafinil & 1.107 & $0.4(4)$ & $0.1(1)$ & $0.1(1)$ & $0.1(1)$ \\
\hline Stimulating illicit drugs & 1118 & $10.2(114)$ & $3.8(42)$ & $1.3(14)$ & $0.6(6)$ \\
\hline Cocaine & 1114 & $6.1(68)$ & $1.9(21)$ & $0.3(4)$ & $0.1(1)$ \\
\hline Amphetamines & 1115 & $6.9(77)$ & $2.5(28)$ & $0.8(9)$ & $0.3(4)$ \\
\hline Meth-Amphetamines & 1111 & $2.0(22)$ & $0.6(6)$ & $0.1(1)$ & $0.1(1)$ \\
\hline Mood modulating prescription drugs & 1110 & $20.3(225)$ & $10.6(118)$ & $5.9(66)$ & $5.6(62)$ \\
\hline Anti-depressant & 1096 & $8.5(93)$ & $4.0(44)$ & $1.6(18)$ & $1.5(16)$ \\
\hline Beta blocker & 1080 & $8.5(92)$ & $5.2(56)$ & $4.1(45)$ & $4.0(43)$ \\
\hline Benzodiazepines & 1088 & $8.9(98)$ & $3.5(38)$ & $0.9(10)$ & $0.7(8)$ \\
\hline Cannabis & 1109 & $23.4(260)$ & $8.6(94)$ & $3.7(40)$ & $2.8(30)$ \\
\hline Any medication or drug & 1121 & $38.8(435)$ & $19.1(214)$ & $10.1(113)$ & $8.5(95)$ \\
\hline
\end{tabular}

$N=1128$

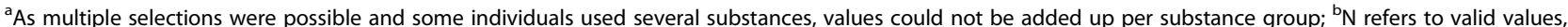
i.e. all observations without missing values in the respective question; 'Weighted according to the distribution of the general population in Germany as reported by the German office of national statistics, $n$ refers to the absolute frequency and \% refers to the relative frequency of participants that have taken the respective substance ever in their life, in the last year, last month or last week

\section{Stress, the ability to recover from stress and resilience} factors as factors explaining substance use for PNE

Prior to multivariate logistic regression analyses, we examined the correlations between predictor variables (BRS, PSS-4, ASKU, SOP-2, IE) to assess for potential multicollinearity (Additional file 2). We found medium to high correlations between the predictor variables (range: -.39 to .62). However, the correlations were below the recommended cut-off (.80) indicating that these variables all assess different constructs and multicollinearity can be excluded. The VIF is $>10$ which is below the recommended cut-off providing additional evidence against multicollinearity.

Table 3 shows the first and the last step of the adjusted multivariate logistic regression model for mood modulating prescription drugs. In that subgroup, only the BRS remained as predictor in the final model (step 6). Thus, the ability to recover from stress, but not the other predictors was the main factor explaining the use of mood modulation prescription drugs. Each additional unit on the BRS (i.e. the increasing ability to recover from stress) decreases the likelihood for the use of mood modulating prescription drugs by $38 \%$ (OR: .62; 95\% CI: .47-.81) (see Table 3 ). The final model explained $36 \%$ of the variance $\left(R^{2}:\right.$.36) (3).

Table 4 shows the first and the last step of the adjusted multivariate logistic regression model for users of stimulating illicit drugs compared to non-users. Only the degree of optimism as measured by the SOP-2 remained as predictor in the final model (step 6). This means that the resilience factor optimism was the main factor explaining stimulating illicit drug use, but not the ability to recover from stress, perceived stress level or the other resilience factors. Here, each additional unit on the SOP-2 (i.e. the increasing level of optimism of the subject) decreased the likelihood for the use of stimulating illicit drugs compared to non-use by $37 \%$ (OR: .63; $95 \%$ CI: .47-.86). The final model explained $45 \%$ of the variance $\left(R^{2}: .45\right)(4)$.

Table 5 shows the first and the last step of the adjusted multivariate logistic regression model for users of cannabis compared to non-users. Here again, only the degree of optimism as measured by the SOP- 2 remained as predictor in the final model (step 6) meaning that the resilience factor optimism, but not the ability to recover from stress, the perceived stress level or the other resilience factors were main factors explaining the use of cannabis.

Overall, each additional unit on the SOP-2 (i.e. the increasing level of optimism of the subject) decreases the likelihood of cannabis use by $26 \%$ (OR: .74; 95\% CI: $.59-.92)$. The final model explained $33 \%$ of the variance $\left(\mathrm{R}^{2}\right.$ : .33) (Table 5).

Table 6 shows the first and the last step of the adjusted multivariate logistic regression model for users of stimulating prescription drugs compared to non-users. Only the level of perceived stress as measured by the PSS-4 remained as predictor in the final model (step 6). This means that perceived stress, but not the ability to recover from stress or any of the resilience factors was the main factor explaining stimulating prescription drug use. 


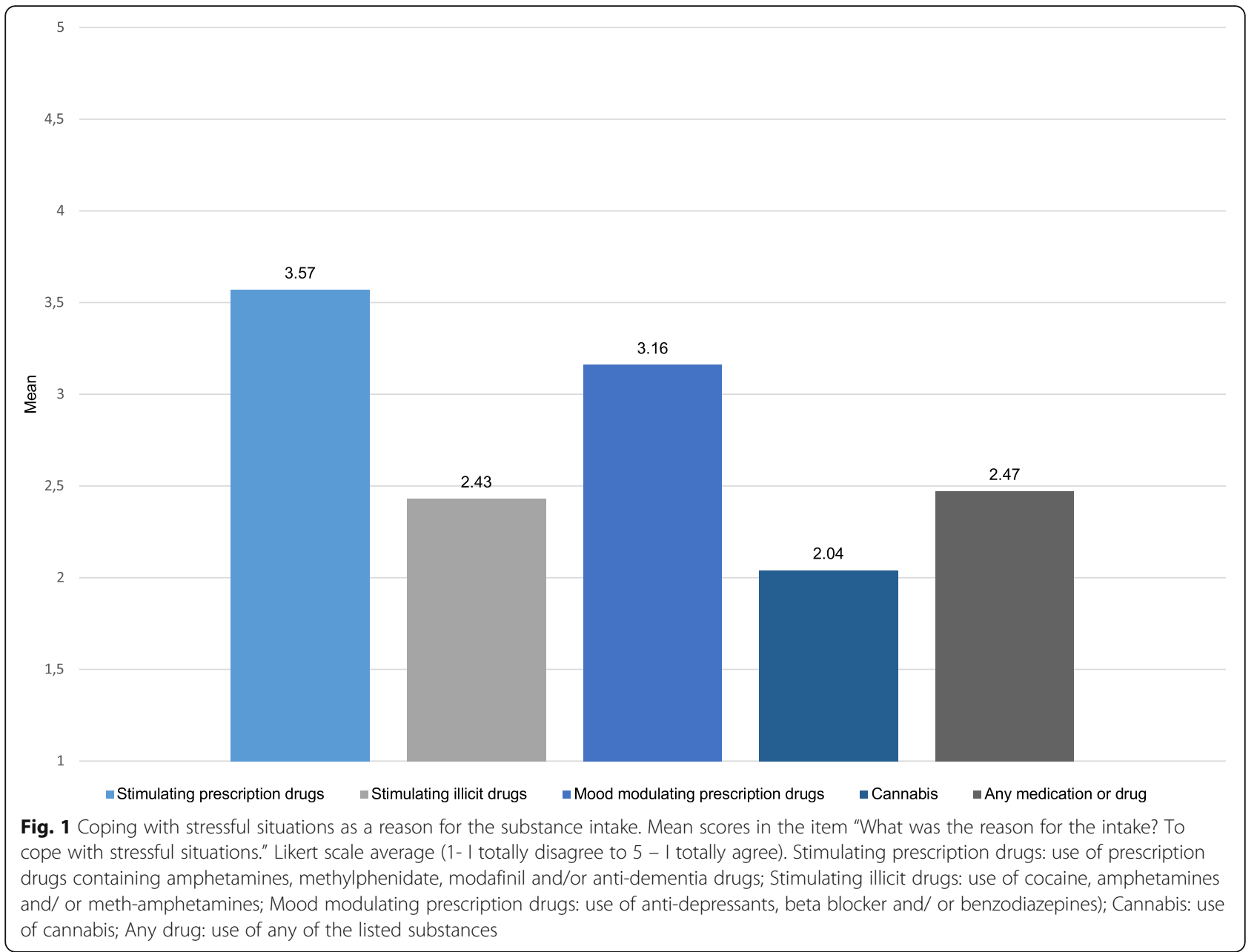

Each unit on the PSS-4 (i.e. the increasing level of perceived stress) increases the likelihood for the use of stimulating prescription drugs almost three times (OR: 2.89; 95\% CI: $1.49-5.46)$. The final model explains $45 \%$ $\left(\mathrm{R}^{2}:\right.$.45) of variance in that subgroup (Table 6).

\section{Discussion}

This is the first study providing data on the use of prescription and illicit drugs for PNE in a representative sample in Germany. In addition, it contributes to previous studies in the field of PNE use by investigating the relationship between PNE use and the ability to recover from stress for the first time.

We found a lifetime prevalence rate of any substance use for PNE of $38.8 \%$ which was higher compared to previous studies (1-20\%) [4, 7, 16-20] . There are several possible explanations for the higher prevalence rates in our survey compared to other studies. First of all, we used a broader definition of PNE which referred not only to PNE use for enhancing cognitive performance but also to improving mood or reducing nervousness without medical indication. This broader definition may explain the higher prevalence rates found in this study by including more users with different motives for the substance intake. In this study, we decided to use a broader definition of PNE since it refers not only to the objective of achieving higher cognitive performance, but also to reaching a mental state which allows coping with daily tasks. In contrast, previous studies only assessed the intake of prescription stimulants $[4,13,19]$ or prescription medication [1].

Second, the use of psychoactive substances varies between different study populations. Previous studies were limited to specific groups such as students or pupils, whereas our survey delivers representative data for the German adult population.

Third, by using a closed envelope technique for sensitive questions, we provided a high degree of confidentiality for the respondents which may have resulted in a higher and more reliable prevalence rate compared to studies using less anonymous techniques. Indeed, previous studies providing a higher degree of confidentiality, such as online surveys or surveys using the randomized response technique, revealed higher prevalence rates 
Table 3 Adjusted multivariate model of factors associated with use of mood modulating prescription drugs

\begin{tabular}{|c|c|c|c|c|c|c|c|c|}
\hline \multirow[t]{2}{*}{ Variables } & \multicolumn{4}{|l|}{$\operatorname{step} 1^{a}$} & \multicolumn{4}{|l|}{ step $6^{a}$} \\
\hline & $\overline{\text { Coeff. (SE) }}$ & OR (95\% CI) & $p$ & VIF & $\overline{\text { Coeff. (SE) }}$ & OR $(95 \%$ CI) & $p$ & $R^{2 b}$ \\
\hline BRS & $-.43(.18)$ & $.65(.46-.93)$ & .02 & 2.02 & $-.48(.14)$ & $.62(.47-.81)$ & $<.001$ & .36 \\
\hline PSS-4 & $-.12(.18)$ & $.88(.63-1.25)$ & .48 & 1.77 & - & - & - & \\
\hline SOP-2 & $-.09(.17)$ & $.91(.65-1.28)$ & .60 & 1.70 & - & - & - & \\
\hline ASKU & $.04(.20)$ & $1.04(.71-1.52)$ & .84 & 1.72 & - & - & - & \\
\hline$|E-|$ & .09 (.18) & $1.09(.77-1.55)$ & .63 & 1.63 & - & - & - & \\
\hline $\mathrm{IE}-\mathrm{E}$ & $.27(.18)$ & $1.31(.92-1.86)$ & .14 & 1.60 & - & - & - & \\
\hline \multicolumn{9}{|l|}{ Sex: } \\
\hline Male & Reference & & & 1.15 & Reference & & & \\
\hline Female & $-.31(.29)$ & $.73(.42-1.29)$ & .28 & & - & - & - & \\
\hline Age & $.54(.20)$ & $1.72(1.16-2.55)$ & .01 & 1.11 & $.53(.20)$ & $1.70(1.15-2.50)$ & .01 & \\
\hline \multicolumn{9}{|l|}{ Education: } \\
\hline No formal degree & Reference & & & 1.11 & Reference & & & \\
\hline Secondary modern school & $-.73(1.45)$ & $.48(.028-8.29)$ & .61 & & - & - & - & \\
\hline Middle school & $-.17(.35)$ & $.84(.42-.1 .69)$ & .63 & & - & - & - & \\
\hline University-entrance diploma & $-.16(.42)$ & $.85(.38-1.93)$ & .70 & & - & - & - & \\
\hline University degree & $-.17(.45)$ & $.84(.35-2.02)$ & .70 & & - & - & - & \\
\hline \multicolumn{9}{|l|}{ Current or last professional position: } \\
\hline Skilled worker & Reference & & & 1.05 & Reference & & & \\
\hline Executive employee & $.12(.57)$ & $1.13(.37-3.44)$ & .83 & & - & - & - & \\
\hline Non-executive employee & $.46(.46)$ & $1.58(.64-3.92)$ & .32 & & - & - & - & \\
\hline Civil servants & $-.33(.77)$ & $.72(.16-.3 .24)$ & .67 & & - & - & - & \\
\hline Self-employed & $.78(.64)$ & $2.17(.62-7.63)$ & .23 & & - & - & - & \\
\hline Other & $.13(.57)$ & $1.14(.37-3.46)$ & .82 & & - & - & - & \\
\hline \multicolumn{9}{|l|}{ Place of residence: } \\
\hline North Rhine-Westphalia & Reference & & & 1.07 & Reference & & & \\
\hline Hamburg & $.55(.78)$ & $1.73(.37-7.98)$ & .48 & & - & - & - & \\
\hline Lower Saxony & $.09(.50)$ & $1.09(.41-2.90)$ & .85 & & - & - & - & \\
\hline Bremen & $.47(1.77)$ & $1.60(.05-51.41)$ & .79 & & - & - & - & \\
\hline Schleswig Holstein & $.27(.71)$ & $1.32(.33-5.24)$ & .70 & & - & - & - & \\
\hline Hesse & $-.24(.56)$ & $.78(.26-2.35)$ & .78 & & - & - & - & \\
\hline Rhineland-Palatine & $.30(.68)$ & $1.35(.36-5.07)$ & .66 & & - & - & - & \\
\hline Baden-Wuerttemberg & $.16(.43)$ & $1.17(.50-2.75)$ & .71 & & - & - & - & \\
\hline Bavaria & $-.13(.43)$ & $.88(.38-2.03)$ & .77 & & - & - & - & \\
\hline Saarland & $-.1 .73(1.49)$ & $.18(.01-3.30)$ & .25 & & - & - & - & \\
\hline Berlin & $-.56(.78)$ & $.57(.12-2.63)$ & .47 & & - & - & - & \\
\hline Brandenburg & $1.18(.76)$ & $3.24(.71-14.81)$ & .13 & & - & - & - & \\
\hline Mecklenburg-Western Pomerania & n. a. & n. a. & n. a. & n. a. & - & - & - & \\
\hline Saxony & $-1.07(.77)$ & $.35(.08-1.56)$ & .17 & & - & - & - & \\
\hline Saxony-Anhalt & $-1.25(.89)$ & $.29(.05-1.65)$ & .16 & & - & - & - & \\
\hline Thuringia & $-2.69(1.34)$ & $.07(.005-.94)$ & .05 & & - & - & - & \\
\hline
\end{tabular}


Table 3 Adjusted multivariate model of factors associated with use of mood modulating prescription drugs (Continued)

\begin{tabular}{|c|c|c|c|c|c|c|c|}
\hline \multirow[t]{2}{*}{ Variables } & \multicolumn{4}{|l|}{ step $1^{a}$} & \multicolumn{3}{|l|}{ step $6^{a}$} \\
\hline & $\overline{\text { Coeff. (SE) }}$ & OR $(95 \% C l)$ & $p$ & VIF & Coeff. (SE) & OR $(95 \% C I)$ & $R^{2 b}$ \\
\hline \multicolumn{8}{|c|}{ Soft enhancer intake: } \\
\hline No & Reference & & & 1.06 & Reference & & \\
\hline Yes & $2.29(.35)$ & $9.89(5.02-19.51)$ & $<.001$ & & $2.25(.34)$ & $9.49(4.86-18.52)$ & .62 \\
\hline \multicolumn{8}{|c|}{$\begin{array}{l}\text { Logistic regression with backward elimination of factors associated with use of mood modulating prescription drugs (users } n=114 ; \text { non-users }=686 \text { ). First step } \\
\text { and final step. n.a. = no data available } \\
{ }^{a} \text { Step } 1 \text { (full model) and step } 6 \text { (reduced model) in multivariate logistic regression using backward variable selection. Predictors were } z \text {-standardized before being } \\
\text { included in regression analysis. Sociodemographic variables significant in the analyses of mean differences (sex, age, education, current or last professional } \\
\text { position, size place of residence, soft enhancer intake) were included as a block in multivariate backward logistic regression. Results are weighted according to the } \\
\text { distribution of the general population in Germany as reported by the German office of national statistics. }{ }^{b} \text { Nagelkerkes } R^{2} \text { in step } 6 \text { of stepwise backward selection; } \\
\text { Coeff. standardised regression coefficient, SE standard error, OR odds ratio, CI confidence interval, } p p \text { value, VIF variance inflation factor (based on multivariate linear } \\
\text { regression), BRS Brief Resilience Scale, PSS-4 Perceived Stress Scale, SOP-2 Optimism-Pessimism-2 Scale, ASKU Short Scale for Measuring General Self-efficacy Beliefs, IE-I } \\
\text { Short Scale for the Assessment of Locus of Control, internal control beliefs; IE-E: Short Scale for the Assessment of Locus of Control, external control beliefs }\end{array}$} \\
\hline
\end{tabular}

with respect to sensitive questions as compared to standard, non-anonymous surveys $[7,15,16]$.

At first sight, cannabis seems to play the most important role for PNE in our survey as we found the highest lifetime prevalence (23\%) compared to other substance groups. However, it is likely that the majority of cannabis users took the substance many years ago only for a short period of time since the last year prevalence already declined to $9 \%$. Last week prevalence (which can be considered as an indicator for current regular use) was only $3 \%$ for cannabis. In comparison, mood modulating prescription drugs seem to play a more important role in everyday life as we found a last week prevalence of $6 \%$.

A major goal of this study was to assess the relationship of substance use and perceived stress, the ability to cope with stress and three resilience factors (self-efficacy, locus of control and optimism [37, 38]). The individual ability to recover from stress (as measured by the BRS) was associated with a lower risk of mood modulating drug use. Furthermore, subjects reporting high perceived stress (as measured by the PSS-4) were more likely to use stimulating prescription drugs such as methylphenidate, modafinil or amphetamines. These results provide evidence for a slightly differential use of stimulating prescription drugs and mood modulating drugs. With regard to the effect sizes, the adjusted multivariate models used explain $36 \%$ of the variance for the use of mood modulating prescription drugs and $45 \%$ of the variance for the use of stimulating prescription drugs. Regarding the predictor variables we found clinical meaningful effects. The OR for each additional unit on the BRS was .62 (a decrease of 38\%) for mood modulating prescription drugs with a $95 \%$ CI of .47 to .81 (53\% to $19 \%)$. This means that there is a $95 \%$ probability that the population parameter lies within the interval, when considering the lower CI that would result in a decrease in the likelihood of $19 \%$. The OR for each additional unit on the PSS-4 was 2.89 (an almost threefold increase) for stimulating prescription drugs with a $95 \%$ CI of 1.49 to 5.46 (a 1.5 to 5.5 -fold increase), which means that when considering the lower CI the likelihood would still be $50 \%$ higher. Our results are also in line with previous research on the effect of risk factors on PNE use. In a previous study on surgeons [16], we found that ORs that were lower or in a similar range (e.g., 'pressure to perform at work': OR 1.29, $95 \%$ CI: 1.00 to 1.67 ; 'gross income': OR $1.34,95 \%$ CI: 1.09 to 1.64$)$.

But nevertheless the use of both substance groups is associated with "stress" in a broader context, as both user-groups named "stress coping" as an important goal for the substance use.

Neither the ability to recover from stress nor perceived stress were associated with the use of stimulating illicit drugs or cannabis in this study. However, in a previous study among German students, participants using cannabis for the purpose of cognitive enhancement reported more stress than non-users as they perceived the pressure to perform as more burdening [48]. Since these analyses referred to different stress measurements and were not controlled for other factors (as in our multivariate model), it is not possible to directly compare the results. We also identified an association between the use of stimulating illicit drugs or cannabis and a higher level of pessimism. This is in line with previous studies describing pessimism as a risk factor of illicit drug consumption [49].

Being pessimistic could be connected with the goal to improve mood which was a more important goal for the use of illicit than for prescription drugs. This could indicate different patterns of substance use: prescription drugs are rather used goal-oriented as an instrument in stressful situations as a coping strategy whereas illicit drugs are rather used with more general underlying goals such as improving mood. This corresponds with results of a study that indicates that stress coping is a more prevalent goal for the use of prescription medication than for the use of illicit drugs. This study also showed that improving mood measured by the goal "euphoria" seems to be more important for the use of illicit drugs than for prescription medication [50]. We did not 
Table 4 Adjusted multivariate model of factors associated with use of stimulating illicit drugs

\begin{tabular}{|c|c|c|c|c|c|c|c|c|}
\hline \multirow[t]{2}{*}{ Variables } & \multicolumn{4}{|l|}{ step $1^{a}$} & \multicolumn{4}{|l|}{ step $6^{\text {a }}$} \\
\hline & $\overline{\text { Coeff. (SE) }}$ & OR $(95 \%$ Cl) & $p$ & VIF & Coeff. (SE) & OR $(95 \%$ Cl) & $p$ & $R^{2 b}$ \\
\hline$\overline{\text { BRS }}$ & $-.14(.24)$ & $.87(.55-1.40)$ & .57 & 1.99 & - & - & - & $\overline{.45}$ \\
\hline PSS-4 & $-.01(.23)$ & $1.00(.64-1.55)$ & .99 & 1.79 & - & - & - & \\
\hline SOP-2 & $-.34(.21)$ & $.71(.48-1.07)$ & .10 & 1.72 & $-.46(.16)$ & $.63(.47-.86)$ & $<.01$ & \\
\hline ASKU & $-.11(.25)$ & $.89(.55-1.45)$ & .65 & 1.71 & - & - & - & \\
\hline$|E-|$ & $.07(.22)$ & $1.07(.69-1.66)$ & .77 & 1.61 & - & - & - & \\
\hline $\mathrm{IE}-\mathrm{E}$ & $.13(.24)$ & $1.13(.71-1.80)$ & .60 & 1.63 & - & - & - & \\
\hline \multicolumn{9}{|l|}{ Sex: } \\
\hline Male & Reference & & & 1.14 & Reference & & & \\
\hline Female & $-1.17(.36)$ & $.31(.15-.63)$ & .001 & & $-1.11(.35)$ & $.33(.17-.66)$ & $<.01$ & \\
\hline Age & $-.90(.26)$ & $.41(.24-.68)$ & .001 & 1.19 & $-.92(.26)$ & $.40(.24-.66)$ & $<.001$ & \\
\hline \multicolumn{9}{|l|}{ Education: } \\
\hline No formal degree & Reference & & & 1.15 & Reference & & & \\
\hline Secondary modern school & $2.80(1.24)$ & $16.48(1.45-187.61)$ & .02 & & $2.65(1.22)$ & $14.09(1.30-152.86)$ & .3 & \\
\hline Middle school & $-.12(.43)$ & $.89(.38-2.07)$ & .78 & & - & - & - & \\
\hline University-entrance diploma & $-.62(.51)$ & $.54(.20-1.45)$ & .22 & & - & - & - & \\
\hline University degree & $-.85(.66)$ & $.43(.12-1.57)$ & .20 & & - & - & - & \\
\hline \multicolumn{9}{|l|}{ Current or last professional position: } \\
\hline Skilled worker & Reference & & & 1.06 & Reference & & & \\
\hline Executive employee & $-.07(.71)$ & $.93(.23-3.70)$ & .92 & & - & - & - & \\
\hline Non-executive employee & $.73(.51)$ & $2.07(.76-5.63)$ & .15 & & - & - & - & \\
\hline Civil servants & $-.07(1.08)$ & $.93(.22-7.74)$ & .95 & & - & - & - & \\
\hline Self-employed & $.78(.84)$ & $2.17(.42-11.2)$ & .35 & & - & - & - & \\
\hline Other & $.39(.61)$ & $1.47(.44-4.89)$ & .53 & & - & - & - & \\
\hline \multicolumn{9}{|l|}{ Place of residence: } \\
\hline North Rhine-Westphalia & Reference & & & 1.10 & Reference & & & \\
\hline Hamburg & $2.20(.95)$ & $9.00(1.39-58.06)$ & .02 & & $2.14(.94)$ & $8.53(1.37-53.35)$ & .02 & \\
\hline Lower Saxony & $-.11(.749$ & $.89(.21-3.83)$ & .89 & & - & - & - & \\
\hline Bremen & $3.35(1.46)$ & $28.36(1.64-491.68)$ & .02 & & $3.22(1.43)$ & $25.08(1.53-411.61)$ & .02 & \\
\hline Schleswig Holstein & $-.37(1.10)$ & $.69(.08-5.91)$ & .74 & & - & - & - & \\
\hline Hesse & $1.00(.62)$ & $2.72(.80-9.23)$ & .11 & & - & - & - & \\
\hline Rhineland-Palatine & $.82(1.00)$ & $2.27(.32-16.04)$ & .41 & & - & - & - & \\
\hline Baden-Wuerttemberg & $.66(.56)$ & $1.93(.64-5.79)$ & .24 & & - & - & - & \\
\hline Bavaria & $.004(.612)$ & $1.00(.30-3.33)$ & .99 & & - & - & - & \\
\hline Saarland & n.a. & n.a. & n.a. & n.a. & n.a. & n.a. & n.a. & \\
\hline Berlin & $1.66(7.43)$ & $5.28(1.23-22.66)$ & .03 & & $1.53(.73)$ & $4.62(1.11-19.27)$ & .04 & \\
\hline Brandenburg & $2.04(1.13)$ & $7.71(.84-70.71)$ & .07 & & - & - & - & \\
\hline Mecklenburg-Western Pomerania & $.86(.86)$ & $2.36(.44-12.83)$ & .32 & & - & - & - & \\
\hline Saxony & $.62(.77)$ & $1.85(.41-8.36)$ & .32 & & - & - & - & \\
\hline Saxony-Anhalt & $-1.43(1.42)$ & $.24(.02-3.89)$ & .31 & & - & - & - & \\
\hline Thuringia & $.02(1.16)$ & $1.02(.11-9.9)$ & .99 & & - & - & - & \\
\hline \multicolumn{9}{|l|}{ Soft enhancer intake: } \\
\hline No & Reference & & & 1.12 & Reference & & & \\
\hline Yes & $3.02(.60)$ & $20.39(6.35-65.52)$ & $<.001$ & & $3.03(.60)$ & $20.73(6.46-66.47)$ & $<.001$ & \\
\hline
\end{tabular}

Logistic regression with backward elimination of factors associated with use of stimulating illicit drugs (users $n=114$; non-users $=686$ ). First step and final step. n.a. $=$ no data available

Further notes see Table 3 
Table 5 Adjusted multivariate model of factors associated with use of cannabis

\begin{tabular}{|c|c|c|c|c|c|c|c|c|}
\hline \multirow[t]{2}{*}{ Variables } & \multicolumn{4}{|l|}{ step $1^{a}$} & \multicolumn{4}{|l|}{ step $6^{a}$} \\
\hline & Coeff. (SE) & OR $(95 \%$ Cl) & $p$ & VIF & Coeff. (SE) & OR $(95 \%$ Cl) & $p$ & $R^{2 b}$ \\
\hline BRS & $-.13(.16)$ & $.88(.64-1.21)$ & .44 & 1.96 & - & - & - & .33 \\
\hline PSS-4 & $-.06(.15)$ & $.94(.70-1.27)$ & .68 & 1.75 & - & - & - & \\
\hline SOP-2 & $-.14(.15)$ & $.87(.66-1.16)$ & .34 & 1.68 & $-.31(.11)$ & $.74(.59-.92)$ & .01 & \\
\hline ASKU & $-.11(.17)$ & $.89(.64-1.25)$ & .51 & 1.73 & - & - & - & \\
\hline $\mid \mathrm{E}-\mathrm{I}$ & $-.12(.15)$ & $.89(.66-1.12)$ & .44 & 1.65 & - & - & - & \\
\hline $\mathrm{IE}-\mathrm{E}$ & $.14(.15)$ & $1.15(.86-1.54)$ & .34 & 1.54 & - & - & - & \\
\hline \multicolumn{9}{|l|}{ Sex: } \\
\hline Male & Reference & & & 1.11 & Reference & & & \\
\hline Female & $-.67(.24)$ & $.51(.32-.82)$ & .51 & & $-.63(.23)$ & $.53(.34-.84)$ & .01 & \\
\hline Age & $-.69(.17)$ & $.50(.36-.70)$ & $<.001$ & 1.14 & $-.68(.17)$ & $.50(.36-.70)$ & $<.001$ & \\
\hline
\end{tabular}

Education:

No formal degree
Secondary modern school
Middle school
University-entrance diploma
University degree
Current or last professional position:
Skilled worker

Executive employee

Non-executive employee

Civil servants

Self-employed

Other

Place of residence:

North Rhine-Westphalia
Hamburg
Lower Saxony
Bremen
Schleswig Holstein
Hesse
Rhineland-Palatine
Baden-Wuerttemberg
Bavaria
Saarland
Berlin
Brandenburg
Mecklenburg-Western Pomerania
Saxony
Saxony-Anhalt
Thuringia
Soft enhancer intake:

Soft enhancer intake:

No

Yes
Skilled worker
Reference

$1.68(.96)$

$5.38(.81-35.62)$

$-.02(.32)$

$.99(.53-1.82)$

$-.14(.37)$

$.87(.42-1.80)$

$.60(.39)$

$1.82(.85-3.90)$

Reference

$-.49(.47)$

$.05(.36)$

$.61(.24-1.53)$

$-.10(.59)$

$1.05(.52-2.14)$

$-.29(.60)$

$.91(.29-2.88)$

$.15(.43)$

$.75(.23-2.43)$

$1.16(.50-2.70)$

Reference

$.94(.69)$

$.01(.45)$

$.29(1.15)$

$.01(.71)$

$.71(.43)$

$1.11(.59)$

$.66(.39)$

$.34(.38)$

$-1.62(1.06)$

$.62(.55)$

$1.63(.72)$

$.31(.73)$

$-.03(.55)$

$-1.87(1.03)$

$-.17(.74)$

Reference

$2.56(.67-9.77)$

$1.01(.42-2.43)$

$1.34(.14-12.60)$

$1.01(.25-4.07)$

$2.04(.87-4.74)$

$3.04(.95-9.74)$

$1.92(.89-4.15)$

$1.40(.67-2.95)$

$.20(.03-1.58)$

$1.86(.63-5.49)$

$5.10(1.24-20.92)$

$1.36(.32-5.72)$

$1.03(.35-3.00)$

$.16(.02-1.17)$

$.84(.20-3.61)$

1.79 (.26)
1.16

Reference

.08

.96

.71

.12
Reference

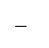

-

$-$

$-$

$-$

1.05 Reference

$\begin{array}{ll}- & - \\ - & - \\ - & - \\ - & - \\ - & - \\ - & - \\ - & - \\ - & - \\ - & - \\ - & - \\ - & - \\ - & - \\ - & - \\ - & - \\ - & -\end{array}$


Table 6 Adjusted multivariate model of factors associated with use of stimulating prescription drugs

\begin{tabular}{|c|c|c|c|c|c|c|c|c|}
\hline \multirow[t]{2}{*}{ Variables } & \multicolumn{4}{|l|}{ step $1^{\text {a }}$} & \multicolumn{4}{|l|}{ step $6^{a}$} \\
\hline & Coeff. (SE) & OR (95\% Cl) & $p$ & VIF & $\overline{\text { Coeff. (SE) }}$ & OR $(95 \%$ Cl) & $p$ & $R^{2 b}$ \\
\hline$\overline{\text { BRS }}$ & $-.72(.42)$ & $.49(.21-1.12)$ & .09 & 2.11 & - & - & - & .45 \\
\hline PSS-4 & $.78(.43)$ & $2.19(.95-5.05)$ & .07 & 1.75 & $1.05(.33)$ & $2.86(1.49-5.46)$ & $<.01$ & \\
\hline SOP-2 & $.01(.38)$ & $1.00(.48-2.13)$ & .98 & 1.76 & - & - & - & \\
\hline ASKU & $.07(.5)$ & $1.07(.40-2.82)$ & .90 & 1.76 & - & - & - & \\
\hline$|E-|$ & $.18(.43)$ & $1.19(.52-2.74)$ & .68 & 1.66 & - & - & - & \\
\hline $\mathrm{IE}-\mathrm{E}$ & $-.16(.38)$ & $.86(.40-1.81)$ & .68 & 1.60 & - & - & - & \\
\hline \multicolumn{9}{|l|}{ Sex: } \\
\hline Male & Reference & & & 1.15 & Reference & & & \\
\hline Female & $-.15(.60)$ & $.86(.27-2.76)$ & .80 & & - & - & - & \\
\hline Age & $-.89(.47)$ & $.41(.17-1.03)$ & .06 & 1.21 & $.53(.20)$ & $1.70(1.15-2.50)$ & $<.01$ & \\
\hline \multicolumn{9}{|l|}{ Education: } \\
\hline No formal degree & Reference & & & 1.11 & Reference & & & \\
\hline Secondary modern school & n.a. & n.a. & n.a. & & - & - & - & \\
\hline Middle school & $-1.21(.83)$ & $.30(.06-1.53)$ & .15 & & - & - & - & \\
\hline University-entrance diploma & $.07(.81)$ & $1.08(.22-5.28)$ & .93 & & - & - & - & \\
\hline University degree & $-.61(1.09)$ & $.54(.06-4.61)$ & .57 & & - & - & - & \\
\hline \multicolumn{9}{|l|}{ Current or last professional position: } \\
\hline Skilled worker & Reference & & & & Reference & & & \\
\hline Executive employee & $2.16(1.25)$ & $8.69(.75-100.30)$ & .08 & 1.05 & - & - & - & \\
\hline Non-executive employee & $1.00(1.15)$ & $2.72(.29-25.62)$ & .38 & & - & - & - & \\
\hline Civil servants & $1.78(1.75)$ & $5.92(.19-181.33)$ & .31 & & - & - & - & \\
\hline Self-employed & $2.74(1.41)$ & $15.44(.98-242.95)$ & .05 & & - & - & - & \\
\hline Other & $1.76(1.42)$ & $5.81(.36-94.30)$ & .22 & & - & - & - & \\
\hline \multicolumn{9}{|l|}{ Place of residence: } \\
\hline North Rhine-Westphalia & Reference & & & 1.10 & Reference & & & \\
\hline Hamburg & $.07(1.55)$ & $1.07(0.05-22.47)$ & .96 & & - & - & - & \\
\hline Lower Saxony & $-1.67(1.59)$ & $.19(.01-4.26)$ & .29 & & - & - & - & \\
\hline Bremen & n.a. & n.a. & n.a. & & - & - & - & \\
\hline Schleswig Holstein & $.17(1.53)$ & $1.18(.06-23.60)$ & .91 & & - & - & - & \\
\hline Hesse & $.10(1.09)$ & $1.10(.13-9.27)$ & .93 & & - & - & - & \\
\hline Rhineland-Palatine & $.70(1.38)$ & $2.01(.13-30.15)$ & .61 & & - & - & - & \\
\hline Baden-Wuerttemberg & $.51(.86)$ & $1.66(.31-9.03)$ & .56 & & - & - & - & \\
\hline Bavaria & $-.61(.97)$ & $.54(.08-3.63)$ & .53 & & - & - & - & \\
\hline Saarland & n.a. & n.a. & n.a. & & - & - & - & \\
\hline Berlin & n.a. & n.a. & n.a. & & - & - & - & \\
\hline Brandenburg & $1.389(2.18$ & $3.98(.06-286.58)$ & .53 & & - & - & - & \\
\hline Mecklenburg-Western Pomerania & n.a. & n.a. & n.a. & & - & - & - & \\
\hline Saxony & $-.09(1.23)$ & $.92(.08-10.23)$ & .94 & & - & - & - & \\
\hline Saxony-Anhalt & n.a. & n.a. & n.a. & & - & - & - & \\
\hline Thuringia & n.a. & n.a. & n.a. & & $-2.62(1.32)$ & $.07(.01-.97)$ & .05 & \\
\hline \multicolumn{9}{|l|}{ Soft enhancer intake: } \\
\hline No & Reference & & & 1.09 & Reference & & & \\
\hline Yes & $2.63(1.12)$ & $13.83(1.55-123.54)$ & .02 & & $2.25(.34)$ & $9.49(4.86-18.52)$ & $<.001$ & \\
\hline
\end{tabular}

Logistic regression with backward elimination) of factors associated with use of stimulating prescription drugs (users $n=48$; non-users $=686$ ). First step and final step. n.a. = no data available

Further notes see Table 3 
find an association of any substance use for PNE with the degree of self-efficacy as was described in an earlier study [51].

This study has several limitations. First, we only assessed adults over 18 years of age which does not allow any conclusions for younger people that were identified as an important at risk population for PNE use [52].

Second, as we conducted the survey with a quota and not a probability sample, our data can only be generalized to the population in Germany, but not to other countries.

Third, in this study we only used the BRS as proxy measure for resilience as outcome by assessing the ability to recover from stress. To date, the BRS is the only scale that was developed based on an outcome definition of resilience [53]. Other existing resilience scales are either based on a trait-oriented approach (e.g., Dispositional Resilience Scale [DRS]) [54] or focus on measuring the availability of resources and protective factors to maintain or regain mental health despite significant adversities (e.g., Connor-Davidson Resilience Scale [CD-RISC]) [55]. To assess resilience as defined (i.e., mental health despite stress), the individual stressor exposure should also be considered when measuring resilience, as suggested by Kalisch and colleagues [56]. As this was not possible in the current study, future representative surveys on resilience and PNE use are required.

Fourth, we did not adjust for multiple testing which may increase the risk of type 1 error inflation. However, our main results regarding the relationship of substance use and perceived stress, the ability to cope with stress and three resilience factors, the respective $p$-values of the odds ratios are between $p=.006$ and $p<.001$. We therefore infer that our main results are robust and not affected by alpha inflation.

Fifth, data were collected cross-sectionally in this study. As a consequence, the analyses are only explorative and causal inferences about the associations found cannot be drawn. The effects of low ability to recover from stress and high perceived stress on PNE use and the potential positive effects of PNE use on these variables cannot be disentangled. This limits the conclusions in this study and underlines the importance of conducting longitudinal studies in this field.

\section{Conclusions}

Based on the results of this study, interventions fostering the ability to recover from stress and reducing perceived stress could have the potential to prevent PNE use at an early stage. We are currently investigating the evidence base (randomized controlled trials) of resilience trainings available so far [57] and have discussed a methodological framework of the suitable design of resilience trainings
[58]. In the future, randomized controlled intervention studies to support the individual ability to recover from stress have to be performed in order to demonstrate that PNE use can be reduced in at risk populations.

In sum, our results provide evidence that PNE is not only used to enhance cognitive performance, improve mood or reduce nervousness, but also to cope with stress. PNE as a strategy for stress management and measures to prevent its intake should be further investigated.

\section{Additional files}

Additional file 1: Sample characteristics per substance group. (DOCX $70 \mathrm{~kb}$ )

Additional file 2: Correlations between the ability to recover from stress, perception of stress and resilience factors. (DOCX $27 \mathrm{~kb}$ )

\section{Abbreviations}

ASKU: Short Scale for Measuring General Self-Efficacy Beliefs; BRS: Brief Resilience Scale; Cl: Confidence intervall; Coeff: Standardised regression coefficient; IE-E: Short Scale for the Assessment of Locus of Control, external control beliefs.; IE-I: Short Scale for the Assessment of Locus of Control, internal control beliefs.; M: Mean; OR: Odds ratio; PNE: Pharmacological neuroenhancement; PSS-4: Perceived Stress Scale; SD: Standard deviation; SE: standard error; SOP-2: Optimism-Pessimism-2 Scale; VIF: Variance inflation factor

\section{Acknowledgements}

The authors want to thank Elisabeth Hildt, Oliver Quiring, Markus Schäfer, Sabine Pohl and Hannes Boelsen for their supportive cooperation within the common research project. We also thank Thomas Petersen from the "Institut für Demoskopie Allensbach" for consulting and data collection and all participating subjects for cooperation.

\section{Funding}

The study was funded by the Federal Ministry of Education and Research No. 01GP1303A (BMBF).

\section{Availability of data and materials}

The datasets used and analysed during the current study are available from the corresponding author on reasonable request.

\section{Authors' contributions}

CB made substantial contributions to conception and design, acquisition of data, analysis and interpretation of data and has been involved in drafting the manuscript. AK made substantial contributions to analysis and interpretation of data and has been involved in drafting the manuscript. JS made substantial contributions to analysis and interpretation of data and has been involved in drafting the manuscript. AGF made substantial contributions to conception and design of data and has been involved in drafting the manuscript. AC made substantial contributions to conception, analysis and interpretation of data and has been involved in drafting the manuscript. KL made substantial contributions to conception and design and has been involved in drafting the manuscript. All authors have given final approval of the version to be published and agreed to be accountable for all aspects of the work.

\section{Ethics approval and consent to participate}

The study was approved by the local Ethics Committee (Landesärztekammer Rheinland-Pfalz, No 837.209.14, 9448F). Participants were informed about the objectives of the study, procedures of data storage, the voluntary nature of study participation and their right to withdraw at any time. Verbal consent was obtained to guarantee confidentiality. 


\section{Competing interests}

The authors declare that they have no competing interests.

\section{Publisher's Note}

Springer Nature remains neutral with regard to jurisdictional claims in published maps and institutional affiliations.

\section{Author details}

'Department of Psychiatry and Psychotherapy, University Medical Center Mainz, Untere Zahlbacher Str. 8, 55131 Mainz, Germany. ${ }^{2}$ German Resilience Center (DRZ) gGmbH, Untere Zahlbacher Str. 8, 55131 Mainz, Germany. ${ }^{3}$ University of Applied Labour Studies, Bundesagentur für Arbeit, Seckenheimer Landstr. 16, D-68163 Mannheim, Germany.

\section{Received: 2 July 2018 Accepted: 7 October 2018}

\section{Published online: 22 October 2018}

\section{References}

1. DAK Versorgungsmanagement. DAK-Gesundheitsreport 2015. Berlin: medhochzwei-Verlag; 2015.

2. Franke AG, Bagusat C, Rust S, Engel A, Lieb K. Substances used and prevalence rates of pharmacological cognitive enhancement among healthy subjects. Eur Arch Psychiatry Clin Neurosci. 2014;264(Suppl 1): S83-90.

3. Greely H, Sahakian B, Harris J, Kessler RC, Gazzaniga M, Campbell P, et al. Towards responsible use of cognitive-enhancing drugs by the healthy. Nature. 2008;456(7223):702-5

4. Franke AG, Bonertz C, Christmann M, Huss M, Fellgiebel A, Hildt E, et al. Non-medical use of prescription stimulants and illicit use of stimulants for cognitive enhancement in pupils and students in Germany. Pharmacopsychiatry. 2011:44(2):60-6.

5. Liakoni E, Schaub MP, Maier LJ, Glauser G-V, Liechti ME. The use of prescription drugs, recreational drugs, and 'soft enhancers' for cognitive enhancement among Swiss secondary school students. PLoS One. 2015 10(10):e0141289.

6. Wolff W, Brand R. Subjective stressors in school and their relation to neuroenhancement: a behavioral perspective on students' everyday life 'doping'. Subst Abuse Treat Prev Policy. 2013;8:23.

7. Dietz P, Striegel H, Franke AG, Lieb K, Simon P, Ulrich R. Randomized response estimates for the 12-month prevalence of cognitive-enhancing drug use in university students. Pharmacotherapy. 2013;33(1):44-50.

8. Eickenhorst P, Vitzthum K, Klapp BF, Groneberg D, Mache S. Neuroenhancement among German University students: motives, expectations, and relationship with psychoactive lifestyle drugs. J Psychoactive Drugs. 2012:44(5):418-27.

9. Lengvenyte A, Strumila R, Grikiniene J. Use of cognitive enhancers among medical students in Lithuania. Nord Stud Alcohol Dr. 2016:33(2):173-87.

10. Maier $\sqcup$, Haug S, Schaub MP. Prevalence of and motives for pharmacological neuroenhancement in Switzerland--results from a national internet panel. Addict Abingdon Engl. 2016;111(2):280-95.

11. Middendorff E, Poskowsky J, Isserstedt W. Formen der Stresskompansation und Leistungssteigerung bei Studierenden. HISBUS-Befragung zur Verbreitung und zu Mustern von Hirndoping und Medikamentenmissbrauch. Hannover: Forum Hochschule; 2012

12. Ram SS, Hussainy S, Henning M, Jensen M, Russell B. Prevalence of cognitive enhancer use among New Zealand tertiary students. Drug Alcohol Rev. 2016;35(3):345-51.

13. Webb JR, Valasek MA, North CS. Prevalence of stimulant use in a sample of US medical students. Ann Clin Psychiatry. 2013;25(1):27-32.

14. Maher B. Poll results: look who's doping. Nature. 2008:452(7188):674-5.

15. Franke AG, Dietz P, Ranft K, Balló H, Simon P, Lieb K. The use of pharmacologic cognitive enhancers in competitive chess. Epidemiol Camb Mass. 2017;28(6): e57-8.

16. Franke AG, Bagusat C, Dietz $P$, Hoffmann I, Simon $P$, Ulrich $R$, et al. Use of illicit and prescription drugs for cognitive or mood enhancement among surgeons. BMC Med. 2013;11:102

17. Castaldi S, Gelatti U, Orizio G, Hartung U, Moreno-Londono AM, Nobile M, et al. Use of cognitive enhancement medication among northern Italian university students. J Addict Med. 2012:6(2):112-7.

18. McCabe SE, Knight JR, Teter CJ, Wechsler H. Non-medical use of prescription stimulants among US college students: prevalence and correlates from a national survey. Addict Abingdon Engl. 2005;100(1):96-106.
19. Smith ME, Farah MJ. Are prescription stimulants 'smart pills'? The epidemiology and cognitive neuroscience of prescription stimulant use by normal healthy individuals. Psychol Bull. 2011;137(5):717-41.

20. Wilens TE, Adler LA, Adams J, Sgambati S, Rotrosen J, Sawtelle R, et al. Misuse and diversion of stimulants prescribed for ADHD: a systematic review of the literature. J Am Acad Child Adolesc Psychiatry. 2008;47(1):21-31.

21. Repantis D, Schlattmann P, Laisney $O$, Heuser I. Modafinil and methylphenidate for neuroenhancement in healthy individuals: a systematic review. Pharmacol Res. 2010;62(3):187-206.

22. Hildt E, Franke AG. Cognitive Enhancement - An interdisciplinary perspective. Netherlands: Springer; 2013

23. Douglas T. Human enhancement and supra-personal moral status. Philos Stud. 2011:162(3):473-97.

24. Wiegel C, Sattler S, Göritz AS, Diewald M. Work-related stress and cognitive enhancement among university teachers. Anxiety Stress Coping. 2016;29(1): 100-17.

25. Schröder H, Köhler T, Knerr P, Kühne S, Moesgen D, Klein M. Der Einfluss psychischer Belastungen am Arbeitsplatz auf das Neuroenhancement empirische Untersuchungen an Erwerbstätigen. BAuA - Bundeanstalt für Arbeitsschutz und Arbeitsmedizin, editor. Dortmund; 2015.

26. Bonanno GA, Westphal M, Mancini AD. Resilience to loss and potential trauma. Annu Rev Clin Psychol. 2011;7:511-35.

27. Feder A, Charney D, Collins K. Neurobiology of resilience. In: Resilience and Mental Health. Cambridge: Cambridge University Press; 2011.

28. Kalisch R, Baker DG, Basten U, Boks MP, Bonanno GA, Brummelmann E, et al. The resilience framework as a strategy to combat stress-related disorders. Nat Hum Behav. 2017;1:784-90.

29. Sapienza JK, Masten AS. Understanding and promoting resilience in children and youth. Curr Opin Psychiatry. 2011;24(4):267-73

30. Bonanno GA, Diminich ED. Annual research review: positive adjustment to adversity - trajectories of minimal-impact resilience and emergent resilience. J Child Psychol Psychiatry. 2013:54(4):378-401.

31. Luthar S, Cicchetti D, Becker B. The construct of resilience: a critical evaluation and guidelines for future work. Child Dev. 2000;71(3):543-62

32. Fletcher D, Sarkar M. Psychological Resilience. Eur Psychol. 2013;18(1):12-23.

33. Rutter M. Resilience in the face of adversity. Protective factors and resistance to psychiatric disorder. Br J Psychiatry J Ment Sci. 1985;147:598-611.

34. Reivich K, Shatté A. The resilience factor: seven essential skills for overcoming life's inevitable obstacles. New York: Broadway Books; 2002

35. Southwick SM, Litz BT, Charney DS, Friedman MJ. Resilience and mental health: challenges across the lifespan. Cambridge: Cambridge Press; 2011.

36. Franke AG, Schwarze C, Christmann M, Bonertz C, Hildt E, Lieb K. Charakteristika von Studierenden, die pharmakologisches Neuroenhancement mit Stimulanzien betreiben: Eine Pilotstudie [characteristics of university students using stimulants for cognitive enhancement: a pilot study]. Psychiatr Prax. 2012;39(04):174-80.

37. Southwick SM, Charney DS. Resilience: the science of mastering life's greatest challenges. Cambridge: Cambridge University Press; 2012.

38. Stewart DE, Yuen T. A systematic review of resilience in the physically ill. Psychosomatics. 2011;52(3):199-209.

39. Destatis. Mikrozensus 2015 [Internet]. 2016 [cited 2017 Sep 1]. Available from: https://www.destatis.de/DE/ZahlenFakten/GesellschaftStaat/Bevoelkerung/ Mikrozensus.html

40. Smith BW, Dalen J, Wiggins K, Tooley E, Christopher P, Bernard J. The brief resilience scale: assessing the ability to bounce back. Int J Behav Med. 2008; 15(3):194-200.

41. Chmitorz A, Wenzel M, Stieglitz R-D, Kunzler A, Bagusat C, Helmreich I, et al. Population-based validation of a German version of the brief resilience scale. PLoS One. 2018;13(2):e0192761.

42. Warttig SL, Forshaw MJ, South J, White AK. New, normative, English-sample data for the short form perceived stress scale (PSS-4). J Health Psychol. 2013;18(12):1617-28.

43. Stächele HP. Taschenatlas Stress. Linkenheim-Hochstetten: Aesopus Verlag; 2013.

44. Beierlein C, Kemper CJ, Kovaleva A, Rammstedt B. Ein Messinstrument zur Erfassung subjektiver Kompetenzerwartungen - Allgemeine Selbstwirksamkeit Kurzskala (ASKU) [Internet]. Köln: GESIS; 2012 [cited 2016 Apr 18]. Available from: https://pub.uni-bielefeld.de/publication/2575629

45. Kovaleva A, Beierlein C, Kemper CJ, Rammstedt B. Eine Kurzskala zur Messung von Kontrollüberzeugung: Die Skala Internale-Externale-Kontrollüberzeugung-4 (IE-4) [Internet]. 2012 [cited 2014 Aug 19]. Available from: http://pub. uni-bielefeld.de/publication/2575676 
46. Kemper CJ, Beierlein C, Kovaleva A, Rammstedt B. Eine Kurzskala zur Messung von Optimismus-Pessimismus - Die Skala Optimismus-Pessimismus-2 (SOP2) [Internet]. Köln: GESIS; 2012 [cited 2014 Aug 19]. Available from: http://pub.unibielefeld.de/publication/2575655

47. Eid M, Gollwitzer M, Schmitt M, Regressionsanalyse M. In: Eid M, Gollwitzer M, Schmitt M, editors. Statistik und Forschungsmethoden. Basel: Beltz Verlag; 2010. p. 602-98.

48. Franke AG, Roser P, Lieb K, Vollmann J, Schildmann J. Cannabis for cognitive enhancement as a new coping strategy? Results from a survey of students at four universities in Germany. Subst Use Misuse. 2016;51(14):1856-62.

49. Wray TB, Dvorak RD, Hsia JF, Arens AM, Schweinle WE. Optimism and pessimism as predictors of alcohol use trajectories in adolescence. J Child Adolesc Subst Abuse. 2013;22(1):58-68.

50. Brand R, Wolff W, Ziegler M. Drugs as instruments: describing and testing a behavioral approach to the study of Neuroenhancement. Front Psychol. 2016;7:1226.

51. Maier LJ, Haug S, Schaub MP. The importance of stress, self-efficacy, and self-medication for pharmacological neuroenhancement among employees and students. Drug Alcohol Depend. 2015;156:221-7.

52. Wilens TE, Gignac M, Swezey A, Monuteaux MC, Biederman J. Characteristics of adolescents and young adults with ADHD who divert or misuse their prescribed medications. J Am Acad Child Adolesc Psychiatry. 2006;45(4): 408-14.

53. Windle G, Bennett KM, Noyes J. A methodological review of resilience measurement scales. Health Qual Life Outcomes. 2011;9:8.

54. Bartone PT. Test-retest reliability of the dispositional resilience scale-15, a brief hardiness scale. Psychol Rep. 2007;101(3(1)):943-4.

55. Connor KM, Davidson JRT. Development of a new resilience scale: the ConnorDavidson resilience scale (CD-RISC). Depress Anxiety. 2003;18(2):76-82.

56. Kalisch R, Müller MB. Tüscher O. A conceptual framework for the neurobiological study of resilience. Behav Brain Sci. 2015:1-49.

57. Helmreich I, Kunzler A, Chmitorz A, König J, Binder H, Wessa M, et al. Psychological interventions for resilience enhancement in adults (protocol). Cochrane Database Syst Rev. 2016.

58. Chmitorz A, Kunzler A, Helmreich I, Tüscher O, Kalisch R, Kubiak T, et al. Intervention studies to foster resilience - a systematic review and proposal for a resilience framework in future intervention studies. Clin Psychol Rev. 2018 Feb 1;59:78-100.

Ready to submit your research? Choose BMC and benefit from:

- fast, convenient online submission

- thorough peer review by experienced researchers in your field

- rapid publication on acceptance

- support for research data, including large and complex data types

- gold Open Access which fosters wider collaboration and increased citations

- maximum visibility for your research: over $100 \mathrm{M}$ website views per year

At $\mathrm{BMC}$, research is always in progress.

Learn more biomedcentral.com/submissions 